\title{
Article \\ Identification of Scopoletin and Chlorogenic Acid as Potential Active Components in Sunflower Calathide Enzymatically Hydrolyzed Extract towards Hyperuricemia
}

\author{
Huining Dai, Shuai Lv, Xueqi Fu * and Wannan Li * \\ Edmond H. Fischer Signal Transduction Laboratory, School of Life Sciences, Jilin University, \\ Changchun 130012, China; daihn18@mails.jlu.edu.cn (H.D.); shuailv20@mails.jlu.edu.cn (S.L.) \\ * Correspondence: fxq@jlu.edu.cn (X.F.); liwannan@jlu.edu.cn (W.L.)
}

check for updates

Citation: Dai, H.; Lv, S.; Fu, X.; Li, W. Identification of Scopoletin and Chlorogenic Acid as Potential Active Components in Sunflower Calathide Enzymatically Hydrolyzed Extract towards Hyperuricemia. Appl. Sci. 2021, 11, 10306. https://doi.org/ 10.3390/app112110306

Academic Editors: António

José Madeira Nogueira

and Andrea Luísa Fernandes Afonso

Received: 1 October 2021

Accepted: 28 October 2021

Published: 3 November 2021

Publisher's Note: MDPI stays neutral with regard to jurisdictional claims in published maps and institutional affiliations.

Copyright: (C) 2021 by the authors. Licensee MDPI, Basel, Switzerland. This article is an open access article distributed under the terms and conditions of the Creative Commons Attribution (CC BY) license (https:/ / creativecommons.org/licenses/by/ $4.0 /)$.
Abstract: It is known that sunflower (Helianthus annuus L.) calathide enzymatically hydrolyzed extract (SCHE) contributes to the regulation of serum uric acid (UA); however, evidence regarding its bioactive components and mechanism are lacking. We identified two water-soluble components (scopoletin and chlorogenic acid) that are abundant in sunflower calathide, especially evaluated for the inhibition of xanthine oxidase $(\mathrm{XO})$ and the expression levels of urate transporters with SCHE. Molecular docking of a chlorogenic acid-XO complex was more stable than that of the Scopoletin-XO, and its binding pockets, which closed the $\mathrm{Mo}=\mathrm{S}$ center, was similar to xanthine pockets. Moreover, chlorogenic acid exhibited stronger inhibition than that of the scopoletin below $260 \mu \mathrm{M}$, despite the $\mathrm{IC}_{50}$ of scopoletin $(577.7 \mu \mathrm{M})$ being lower than that chlorogenic acid $(844.7 \mu \mathrm{M})$ on the UA generation assessed by a spectrophotometer in vitro. It revealed that chlorogenic acid and scopoletin were competitive inhibitors of XO. In addition, the SCHE $(300 \mu \mathrm{g} / \mathrm{mL})$ and chlorogenic acid $(0.75 \mathrm{mM})$ obviously inhibited urate transporter 1 (URAT1) and glucose transporter 9 (GLUT9) expression levels, while scopoletin significantly upregulated the expression of GLUT9. To summarize, chlorogenic acid served a crucial role in UA regulation consistent with the SCHE and functioned as an important ingredient of SCHE. The strategic analysis of SCHE combined with scopoletin and chlorogenic acid may contribute to the development of food supplemental alternatives on UA metabolism and the reduction of agricultural byproduct waste.

Keywords: sunflower calathide; scopoletin; chlorogenic acid; urate transporters; xanthine oxidase inhibitor; molecular docking

\section{Introduction}

With the incremental incidence of hyperuricemia (HUA), a metabolic disorder of uric acid (UA), that has attracted great attention in the past few decades, clinical trials and medical research regarding UA regulation became topics of current interest [1]. As it is well known, HUA is a metabolic disease caused by a decrease in UA excretion or an increase in the production of UA due to purine metabolism disorders, and is associated with the incidence of metabolic syndrome, diabetes, hypertension, and kidney disease [2,3]. However, traditional clinical medicine, such as benzbromarone (inhibitor of URAT1), allopurinol, and febuxostat (inhibitor of xanthine oxidase) [4], present potential damaging side effects, such as hepatotoxicity and nephrotoxicity. In addition to changes in lifestyle, medical treatment is typically required for hyperuricemia. On account of the side effects of the medication, natural and functional food could be an option for the development of alternative therapies.

Sunflower (Helianthus annuus L.) calathide, a type of Chinese folk medicine, has been used for the treatment of hypertension, headache, and analgesic and hemostatic disorders according to the Chinese Materia Medica and the Dictionary of Traditional Chinese Medicine. Admittedly, sunflower head pectin has long been used in functional foods $[5,6]$, 
and natural low-methoxyl pectin, which possesses nutritional effects extracted from the sunflower head, could be used as a potential low-calorie or sugar-free food in the health care industry [7]. Although Chinese researchers have not only found its benefits in the field of hyperuricemia and gout [8], but also revealed the inhibitory effects of sunflower calathide on the expression of urate transporter (URAT1) and the activity of xanthine oxidase (XO) in mice [9], the active components and mechanism of actions still remain unknown. On the one hand, the current animal models regarding hyperuricemia and gout cannot mimic human disease well, because of the presence of uricase in mice [10], even if some employed uricase knockout mice without reliable arguments [11]; on the other hand, human kidneys that developed hyperuricemia were difficult to obtained for further research. Thus, a proper carrier chosen from human-derived cell lines was significant for research on human urate transporters. Accordingly, human embryonic kidney 293T cells expressed URAT1 (SLC22A12) stably [12] and there was a successful exploration involved in glucose transporter 9 (GLUT9) on UA-induced HEK293T cells [13]. Additionally, the protective effect on $\mathrm{H}_{2} \mathrm{O}_{2}$-induced kidney damage was evaluated by HEK293T cells [14], so that it could be employed to detect the oxidative stress involved in UA stimulation. In these cases, we considered 293T cells as a potential experimental model to investigate urate transporters in the human kidney.

In this study, the inhibition of $\mathrm{XO}$, which promotes the generation of xanthine and UA [15], was also considered as therapeutic targets. We identified scopoletin and chlorogenic acid through UPLC-Q-Orbitrap [16] and validated the inhibition of xanthine oxidase in vitro as well as employing AutoDock Tools, an efficient molecular docking approach for virtual screening, to predict the protein-ligand binding interactions [17] and the type of inhibition. Especially, the high UA exposed model was established to evaluate the bioactivity of the extract of Helianthus annuus L. calathide combined with scopoletin and chlorogenic acid. The comprehensive evaluation of the anti-hyperuricemic effect of the SCHE would contribute to the development of nutritional supplements in alternative therapy.

\section{Materials and Methods}

\subsection{Preparation of Primary Extract (SCHE)}

The sunflower calathide obtained from Baicheng city, Jilin Province $\left(123^{\circ} 12^{\prime} 45^{\prime \prime}\right.$ E, $44^{\circ} 52^{\prime} 23^{\prime \prime}$ N), was identified by Professor Shuwen Guan (School of Life Sciences, Jilin University). The sun-dried sunflower calathide was crushed in a grinder. Subsequently, the sun-dried sunflower calathide coarse powder was crushed and sieved through a 100-mesh screen and, then, $600 \mathrm{~mL}$ distilled water were added to $50 \mathrm{~g}$ of the powder $(1: 12, w: v)$, along with $0.5 \mathrm{~g}$ cellulase (Aladdin, $\mathrm{SHH}, \mathrm{CHN}$ ) to weaken the cell walls. A hydrolysis reaction was performed at $50{ }^{\circ} \mathrm{C}$ for $4 \mathrm{~h}$, followed by the adding of $1 \mathrm{~g} \mathrm{CaCl}_{2}(\mathrm{GHTECH}$, $\mathrm{GD}, \mathrm{CHN}$ ) to remove the pectin. After being filtrated and centrifuged for $10 \mathrm{~min}$ at $2000 \times g$, the solution was collected and dried with a spray-dryer to yield $15 \mathrm{~g}$ sunflower calathide powder. The extracted SCHE powder was stored at $-80^{\circ} \mathrm{C}$ and resuspended in accordance with the experimental requirements.

\subsection{Identification by UPLC-Q-Orbitrap MS}

The extract was identified by ultra-high-performance liquid chromatography-quadrupoleOrbitrap mass spectrometry (UPLC-Q-Orbitrap MS) and compared with reference standards. The $200 \mathrm{mg}$ SCHE powder was dissolved with a $1 \mathrm{~mL}$ methanol (ThermoFisher, Waltham, USA) solution (methanol:water, 8:2, v:v), centrifuged at 20,000 $\times g$ for $10 \mathrm{~min}$, and filtered through a $0.22 \mu \mathrm{m}$ PES membrane. Scopoletin (HPLC $\geq 98 \%$, Solarbio, BJ, CHN) and chlorogenic acid (3-Caffeoylquinic acid, HPLC $\geq 98 \%$, Aladdin, $\mathrm{SHH}, \mathrm{CHN}$ ) were dissolved in methanol and sonicated for $5 \mathrm{~min}$ to obtain a standard stock solution with a concentration of $20 \mu \mathrm{g} / \mathrm{mL}$.

For this analysis, the phase A consisted of $0.1 \%(v: v)$ formic acid (ThermoFisher, Waltham, USA) and water; phase B consisted of $0.1 \%$ (v:v) formic acid and acetonitrile (ThermoFisher, Waltham, USA). The injection volume of SCHE and standard solutions were 
set at $5 \mathrm{uL}$; meanwhile, a flow rate of $0.300 \mathrm{~mL} / \mathrm{min}$ and a 5 min gradient at $10^{\circ} \mathrm{C}$ were fixed (RP-C18, $150 \times 2.1 \mathrm{~mm}$ i.d., $1.8 \mu \mathrm{m}$, Welch, NYC, USA). The gradient elution was performed under the following conditions: $98 \%$ phase A (0-1 $\mathrm{min}), 98-80 \%$ phase A ( $1-5 \mathrm{~min}), 80-50 \%$ phase A (5-10 $\mathrm{min}), 50-20 \%$ phase A (10-15 $\mathrm{min}), 20-5 \%$ phase A (15-20 $\mathrm{min}), 5 \%$ phase A (20-25 $\mathrm{min}), 5-98 \%$ phase A (25-26 $\mathrm{min})$, and $98 \%$ phase A (26-30 min). The mass spectrometry apparatus was equipped with a Q Exactive (ThermoFisher, Waltham, USA) ESI source and operated in a positive and negative ion mode within a scan range of $150 \sim 2000 \mathrm{~m} / z$ for $30 \mathrm{~min}$. The conditions were performed as follows: spray voltage, $3.8 \mathrm{kV}$ (positive); capillary temperature, $300{ }^{\circ} \mathrm{C}$; collision gas, argon ( $\geq 99.999 \%$ purity); sheath gas and auxiliary gas $\left(350^{\circ} \mathrm{C}\right)$, nitrogen $(\geq 99.999 \%$ purity).

\subsection{Cell Culture}

The HEK (human embryonic kidney) 293T cells obtained from the cell bank of the Chinese Academy of Sciences (Shanghai, China) were cultured in DMEM (HyClone, UT, USA) with $10 \%$ FBS (ABW, URY) and 1\% penicillin/streptomycin (Solarbio, BJ, CHN, and maintained at $37{ }^{\circ} \mathrm{C}$ in an incubator with $5 \% \mathrm{CO}_{2}$. The cells at the logarithmic growth phase were seeded in 6 wells $\left(5 \times 10^{5}\right.$ cells/well $)$ and 96 wells $\left(3 \times 10^{4}\right.$ cells/well $)$ plates overnight before treatment. The cells were divided into control group (untreated), UA (Sigma-Aldrich, MO, USA) group (1 mM), SCHE group $(300 \mu \mathrm{g} / \mathrm{mL})$, chlorogenic acid (CA) group $(0.75 \mathrm{mM})$, and scopoletin (SP) group $(0.27 \mathrm{mM})$. The cells were pretreated with SCHE, CA, and SP, respectively, for $3 \mathrm{~h}$ before being $1 \mathrm{mM}$ UA stimulated.

\subsection{Generation of Reactive Oxygen Species (ROS)}

After a $24 \mathrm{~h}$ treatment, the HEK293T cells, which were divided into control, UA, SCHE, $\mathrm{CA}$, and SP groups, were incubated with $10 \mu \mathrm{M} 2^{\prime} 7^{\prime}$-dichlorofluorescein diacetate (DCFHDA) (Sigma-Aldrich, $287810, \mathrm{MO}$, USA) for $30 \mathrm{~min}$ at $37^{\circ} \mathrm{C}$. Then, they were washed three times with PBS to remove excess DCFH-DA and excited by blue light $(488 \mathrm{~nm})$ with a $200 \times$ fluorescence microscopy (Echo Revolve FL, CA, USA).

\subsection{Western Blot}

The 293T cells were washed with PBS and lysed with a lysis buffer (Solarbio, BJ, $\mathrm{CHN}$ ) containing $1 \%$ protease inhibitor on ice for $30 \mathrm{~min}$, followed by centrifugation at $8000 \times g$ for $15 \mathrm{~min}$ to collect the protein supernatant. A 10\% electrophoresis gel was prepared with $5 \%$ concentrated glue. The protein samples were run at a constant pressure of $120 \mathrm{~V}$ and ice-cold, transferred at constant current of $200 \mathrm{~mA}$ for $40 \mathrm{~min}$ on to the PVDF membrane (Millipore, Bedford, MA, USA), followed by $5 \%$ BSA (MYMTech, Hyderabad, India) blocking at room temperature for $1 \mathrm{~h}$. The primary antibodies of ABCG2 (Novus, NB600-1079, CO, USA), URAT1 (Proteintech, 14937-1-AP, CHI, USA), GLUT9 (Novus, NBP1-05054SS, CO, USA), and $\beta$-Actin (CST, 8H10D10, BST, USA) were diluted with $5 \%$ BSA and incubated overnight at $4{ }^{\circ} \mathrm{C}$, after which the secondary antibodies (anti-rabbit $\operatorname{IgG}$, HRP-linked, CST-7074, BST, USA; and anti-mouse IgG $\kappa$, BP-HRP, Santa Cruz-sc-516102, Dallas, USA) were diluted with $1 \%$ BSA (1:2000 dilution) and incubated at $37{ }^{\circ} \mathrm{C}$ for $40 \mathrm{~min}$. The membranes were washed with $1 \times$ TBST (tris-buffered saline with Tween 20) three times before and after antibody incubations. The targets were visualized using a hypersensitive ECL kit (Solarbio, PE0010A/B, BJ, CHN).

\subsection{Effect of XO Inhibition In Vitro}

An enzymatic reaction system was stably established based on the formation of UA catalyzed by XO (Roche, Switzerland). First, $0.02 \mathrm{U} / \mathrm{mL}$ XO were added to the system containing the substrate $(0.5 \mathrm{mM}$ concentration of xanthine, Aladdin, $\mathrm{SHH}, \mathrm{CHN})$ and inhibitors (concentrations of 1040, 520, 260, 130, 65, and $32 \mu \mathrm{M}$, respectively) followed by catalytic reactions for $25 \mathrm{~min}$ at room temperature $\left(25^{\circ} \mathrm{C}\right)$. Subsequently, the formations of 
UA were measured by a spectrophotometer at $290 \mathrm{~nm}$ in triplicate and the inhibition was calculated on the basis of the following formula:

$$
\text { Inhibition }=1-(\mathrm{A} 1-\mathrm{A} 2 / \mathrm{A} 3-\mathrm{A} 4)
$$

A1: OD290nm of solution containing the inhibitor, xanthine, and XO.

A2: OD290nm of solution containing the inhibitor and xanthine.

A3: OD290nm of solution containing xanthine and XO.

A4: OD290nm of solution only containing xanthine.

\subsection{Semi Flexible Docking of Xanthine Oxidase (XO)}

The crystal structures of macromolecules (PDB ID:3NVW) were obtained from the Protein Data Bank; meanwhile, the 3D structures of the ligands (scopoletin, ChemSpider ID:4444113; and chlorogenic acid, ChemSpider ID:1405788) were retrieved from ChemSpider. Water molecules and hetero atoms were eliminated for docking calculation. Thereafter, the AutoDock Tools (ADT) 1.5.6 was employed to add hydrogens and compute Gasteiger charges. The grid boxes of $60 \times 56 \times 50$ points and $54 \times 52 \times 42$ points with $0.375 \AA$ spacing were used for calculating scopoletin and chlorogenic acid, respectively. Accordingly, the molecular docking was performed by AutoDock 4 along with AutoGrid 4.2.6 software (Numeca International, Belgium, 2009) and other parameters used default values. Furthermore, the results were visualized and analyzed by PyMOLWin.

\subsection{Statistical Analysis}

All the experimental data were analyzed by GraphPad Prism Version 8.2.1 for Mac (GraphPad Software, La Jolla, CA, USA), and expressed as the mean \pm SD. One-way ANOVA was applied to determine the differences in ROS. Signal intensities in Western blotting and fluorescence assays were measured by Image J. $p$ value less than 0.05 was considered statistically significant.

\section{Results}

\subsection{Total Ion Chromatograms (TIC)}

The major constituents in sunflower calathide enzymatic hydrolyzed extract (SCHE) were characterized by UPLC-Q-Orbitrap MS. A total ion chromatogram of the SCHE was characterized both in the positive and negative ion modes (Figure 1a). In the MS ${ }^{2}$ spectrum, the compound of interest, which yielded a fragment ion at $m / z 193.05[\mathrm{M}+\mathrm{H}]^{+}, m / z 178.03$, $m / z$ 137.06, and $m / z$ 133.03, was preliminary identified as scopoletin compared with the database. Likewise, chlorogenic acid was initially identified according to the database, corresponding to the fragment ion at $m / z 353.09, m / z 291.13, m / z 191.05, m / z 179.03$, and $\mathrm{m} / z$ 135.04. Additionally, it required a further verification based on comparison with the authentic standards.

\subsection{Identification and Quantification of Scopoletin and Chlorogenic Acid}

Comparing the peak intensity under the same liquid chromatography conditions with the authentic standards, the retention times of the sample indicated that $\mathrm{RT}_{\mathrm{a}}=8.40 \mathrm{~min}$ (Figure 2a) and $\mathrm{RT}_{\mathrm{b}}=6.57 \mathrm{~min}$ (Figure $2 \mathrm{~b}$ ), which were consistent with that of the standards (Rt $=8.41,6.73 \mathrm{~min}$, respectively). Furthermore, the $\mathrm{m} / \mathrm{z}$ of the samples $[(\mathrm{a}) \mathrm{m} / \mathrm{z}=193.0$ and (b) $m / z=355.1$ ] agreed with that of the standards. Eventually, the two water-soluble compounds were identified as scopoletin and chlorogenic acid in the positive ion mode. The manual integration of the peak area was calculated by Xcalibur 4.1 (Thermo) and represented as the relative contents of scopoletin and chlorogenic acid. As it was observed, the relative abundance $\left(\mathrm{MA}_{\text {sample }} / \mathrm{MA}_{\text {standard }}\right)$ of scopoletin and chlorogenic acid reached 1.69 and 0.46 , respectively, which were converted to 879.43 and $129.83 \mu \mathrm{M} / \mathrm{g}$ of the SCHE, respectively. 
(a)

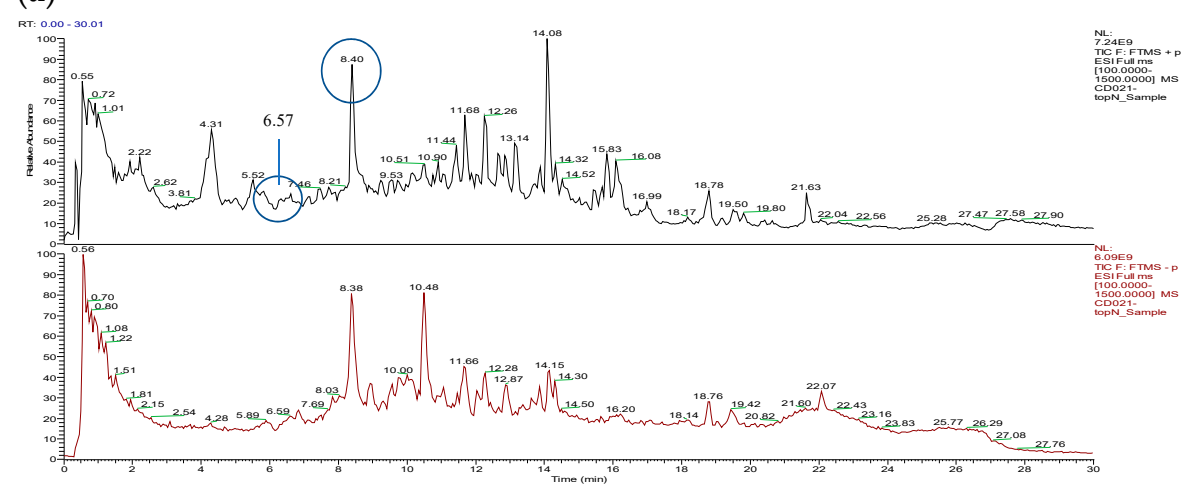

(b)

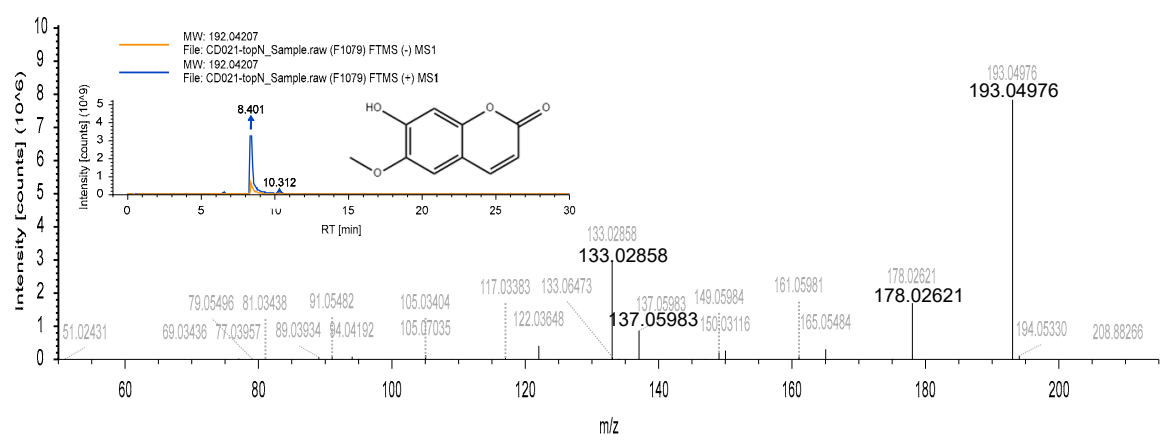

(c)

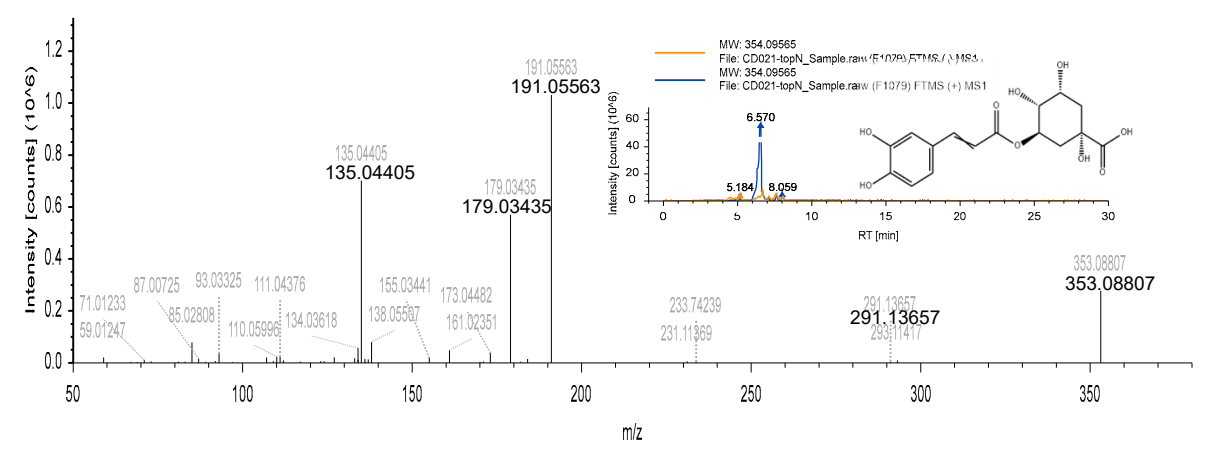

Figure 1. The total ion chromatograms of the SCHE (a) as well as the mass spectrometry of scopoletin (b) and chlorogenic acid (c).

\subsection{Semi-Quantitative Analysis of ROS Generation}

Green fluorescence produced from oxidative DCFH was observed under an inverted microscope $(200 \times)$ and represented the intracellular ROS generation. The fluorescence intensity of the UA treatment was evidently stronger than that of the control group. In contrast, the SCHE $(300 \mu \mathrm{g} / \mathrm{mL})$ treatment displayed reduced fluorescence, and the signal intensity was further eliminated with CA $(0.75 \mathrm{mM})$ and $\mathrm{SP}(0.27 \mathrm{mM})$ treatment, indicating less oxidative stress generation (Figure 3). Moreover, the morphological structure of HEK293T cells fused into a sheet-like shape after being incubated with DCFH-DA.

\subsection{Modulation of Urate Transporters}

As shown in Figure 4b, there was an increase in URAT1 and GLUT9 levels in the UA group. The downregulation of URAT1 appeared in the SCHE $(300 \mu \mathrm{g} / \mathrm{mL})$ and CA $(0.75 \mathrm{mM})$ treatment groups compared to the UA group, and the expression of GLUT9 (Figure 4a) in the SCHE and CA groups were both attenuated distinctly in parallel. On the contrary, the SP $(0.27 \mathrm{mM})$ treatment displayed an upregulation of GLUT9 compared to that of the remaining groups. 


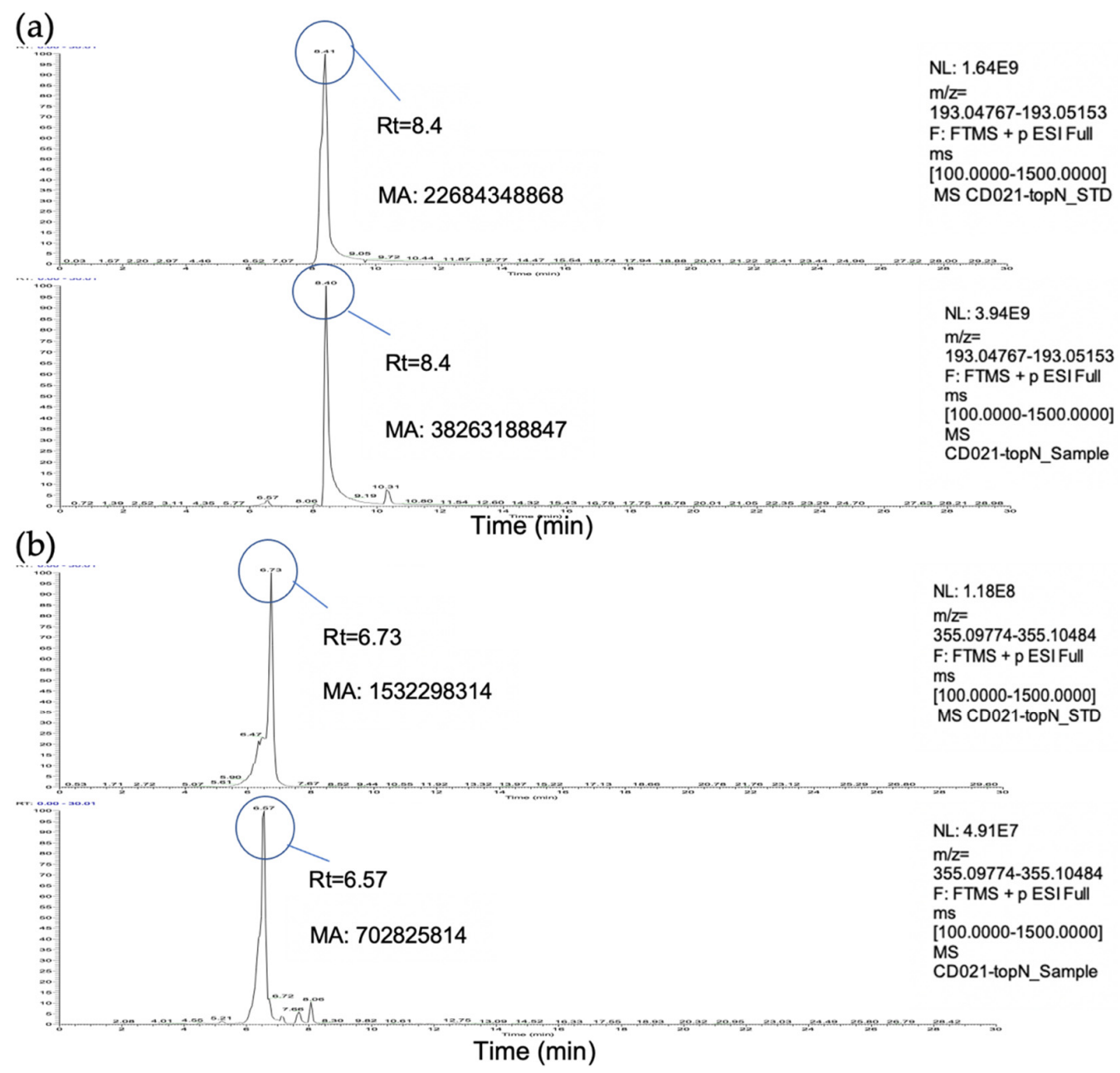

Figure 2. The LC-MS chromatograms of scopoletin (a) and chlorogenic acid (b).
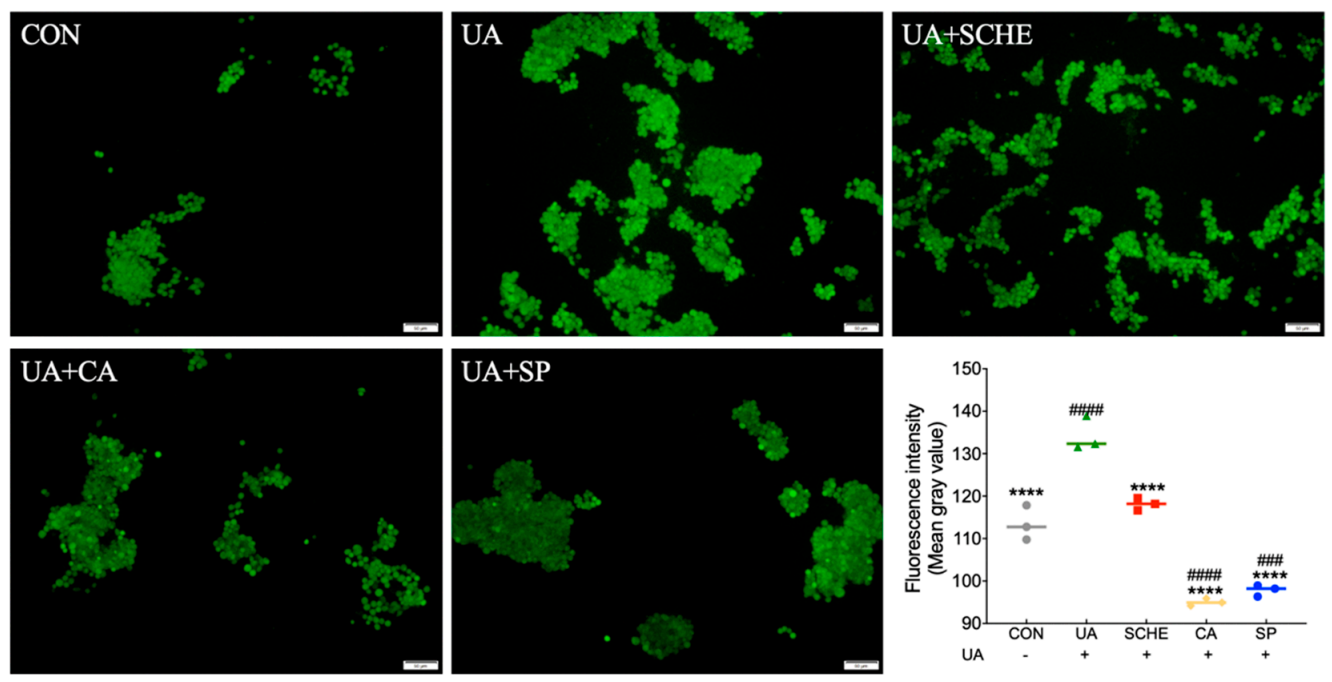

Figure 3. Single-channel fluorescence images on UA-induced $293 \mathrm{~T}$ cells $(200 \times)$. The cells were stimulated by $1 \mathrm{mM}$ UA except for the control group. The gray scales were analyzed by Image J and represented as the mean and scatter of no less than three repeated experiments (\#\#\# $p<0.001$, \#\#\# $p<0.0001$ vs. control group; ${ }^{* * * *} p<0.0001$ vs. UA treatment). 


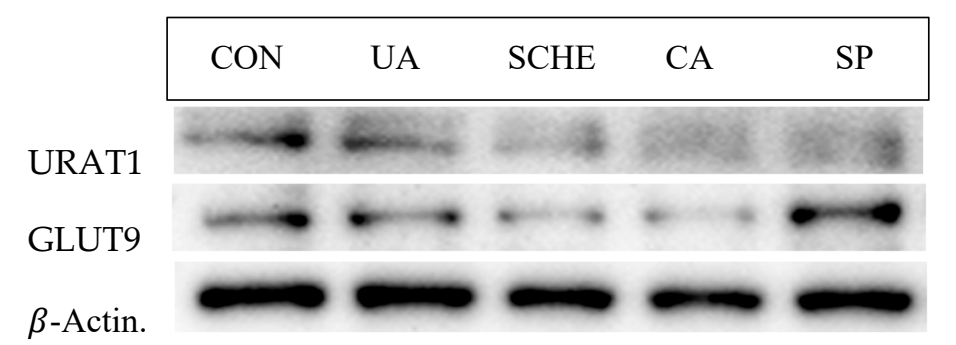

(a)

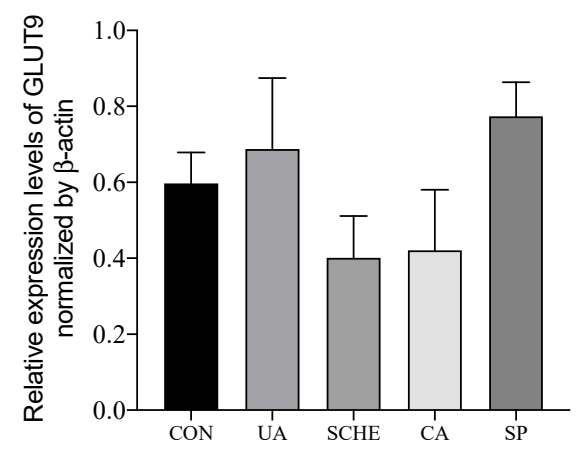

(b)

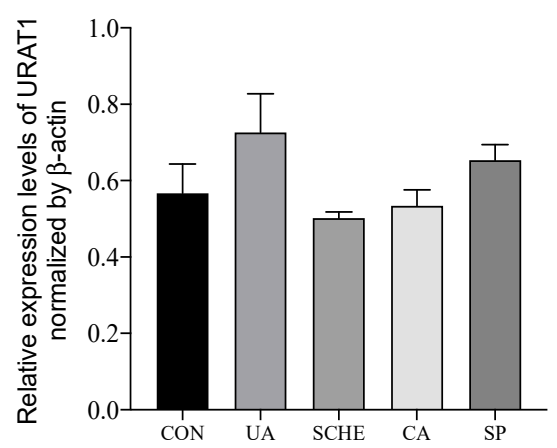

Figure 4. Expression levels of GLUT9 (a) and URAT1 (b), detected in UA-induced HEK293T cells. Bar graphs represent the relative expression levels and were calculated by Image J, as well as the error bars that indicate the mean $\pm \mathrm{SD}$.

\subsection{Inhibitory Effects of Compounds on UA Formation}

After 25 min enzymatic reactions of xanthine $(0.5 \mathrm{mM})$ and $\mathrm{XO}(0.02 \mathrm{U} / \mathrm{mL})$, the formation of UA under different concentrations $(1040,520,260,130,65$, and $32 \mu \mathrm{M}$ respectively) of SP and CA were measured at $290 \mathrm{~nm}$ and represented as the inhibition of XO. The generation of UA decreased with both compounds in a concentration-dependent manner (Figure 5a). The UA formation in the SP treatment was more than that of the CA when the concentrations were below $260 \mu \mathrm{M}$. Beyond $260 \mu \mathrm{M}$, SP showed stronger inhibition than that of the CA treatment. As shown in Figure $5 \mathrm{~b}$, the $\mathrm{IC}_{50}$ was calculated as $577.7 \mu \mathrm{M}$ and $844.7 \mu \mathrm{M}$ for SP and CA respectively (Figure $5 b$ ).
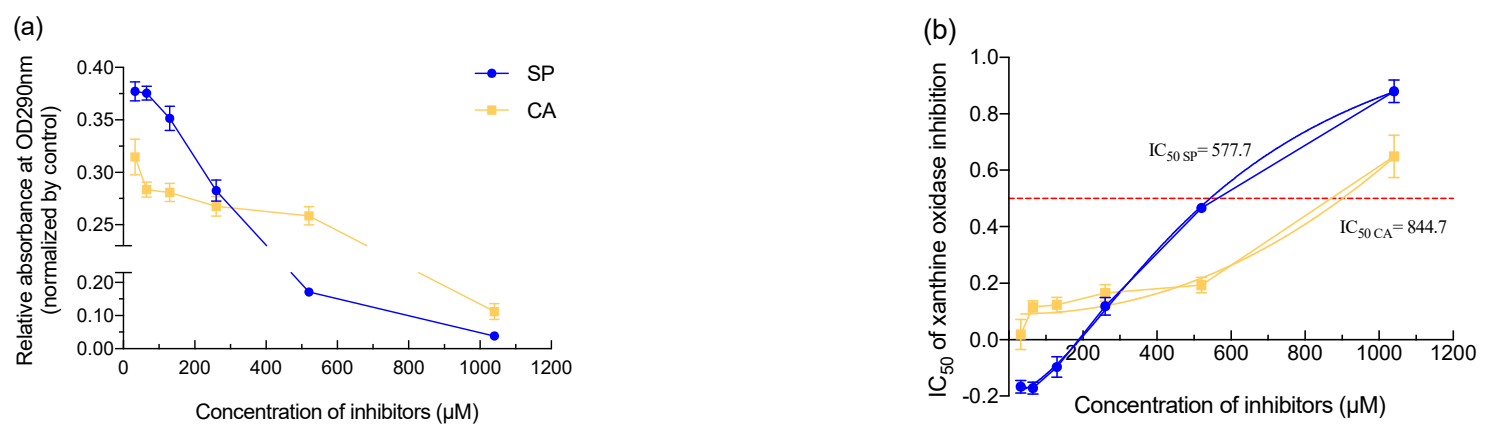

Figure 5. (a) Relative abundance of scopoletin (blue) and chlorogenic acid (yellow) on XO-catalyzed UA formation. (b) Inhibition of scopoletin (blue) and chlorogenic acid (yellow). $\mathrm{IC}_{50}$ : concentration of the compounds, which induced $50 \%$ inhibition of UA formation. Symbols represent the data under corresponding concentrations and error bars indicate the mean \pm SD.

\subsection{Molecular Docking and Residue Interactions}

The natural ligand of $X O$ was removed from the complex $\mathrm{PDB}$ structure $3 \mathrm{NVW}$ and the ligand-free protein was used for docking. The inhibitors were docked to XO with AutoDock Tools 1.5.6 software (The Scripps research institute, CA, US, 2009). The estimated binding free energy between chlorogenic acid and $X O(-6.75 \mathrm{kcal} / \mathrm{mol})$ was lower than that of scopoletin- XO $(-5.65 \mathrm{kcal} / \mathrm{mol})$, and the inhibition constant of CA $(11.18 \mu \mathrm{M})$ was far 
less than that of SP $(72.80 \mu \mathrm{M})$, which was consistent with the inhibition tendency of the experimental data below $260 \mu \mathrm{M}$.

The docking sites of complexes displayed in spheres intuitively revealed the binding pockets (Figure 6a,b). Accordingly, the interactions of SP within $4.00 \AA$ showed critical residues Glu1261, Glu802, Phe798, Phe914, Ala910, Ala1078, and Ala1079 (Figure 6a), which are common residues surrounding the xanthine binding pockets [18]. Furthermore, it formed three hydrophobic interactions with Ala910, Ala1078, and Arg912 (three Pi-Alkyl), one conventional hydrogen bond with Ala1079, two Pi-Anion interactions, and a carbon hydrogen bond with Phe798 (Figure 6a). Meanwhile, the residues of CA within $4.00 \AA$ found the similar residues (Ser1080, Ser1082, Glu1261, Thr1077, and Phe798) observed around the xanthine pocket as well (Figure 6b). Furthermore, five conventional hydrogen bonds with Ser1082, Ser1080, Thr1077, Gln1194, and Met1038, and one hydrophobic interaction with Phe798 were visualized by PyMOL (Figure 6b). The more hydrogen bonds between inhibitor and $\mathrm{XO}$ that there are, the more stable the enzyme and inhibitor system is. CA, apparently, compared to SP and CA, with more hydrogen bonds would more prefer to dock to $\mathrm{XO}$.

(a)

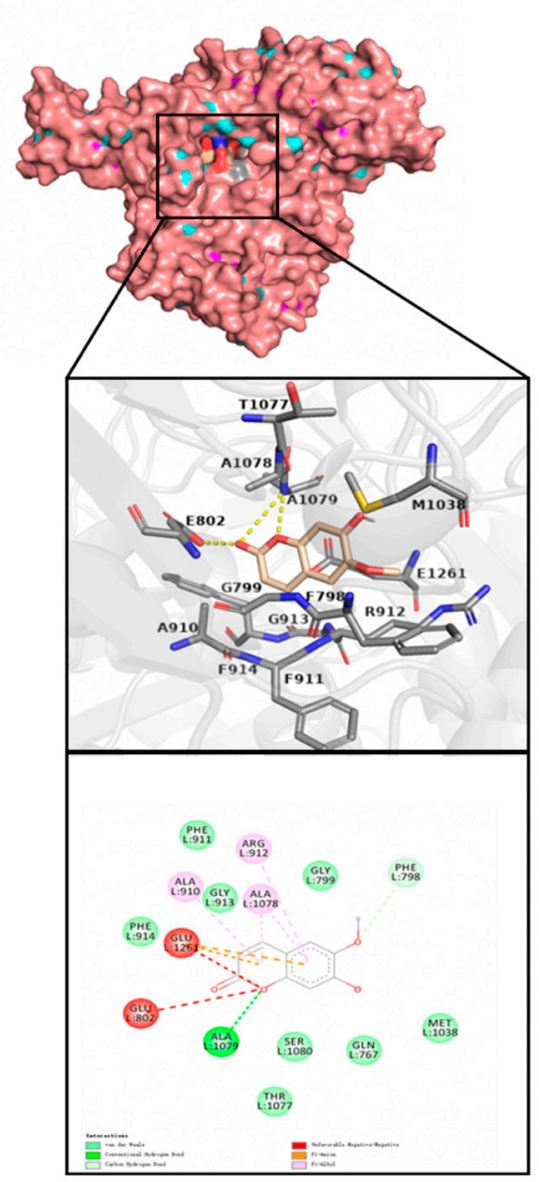

(b)

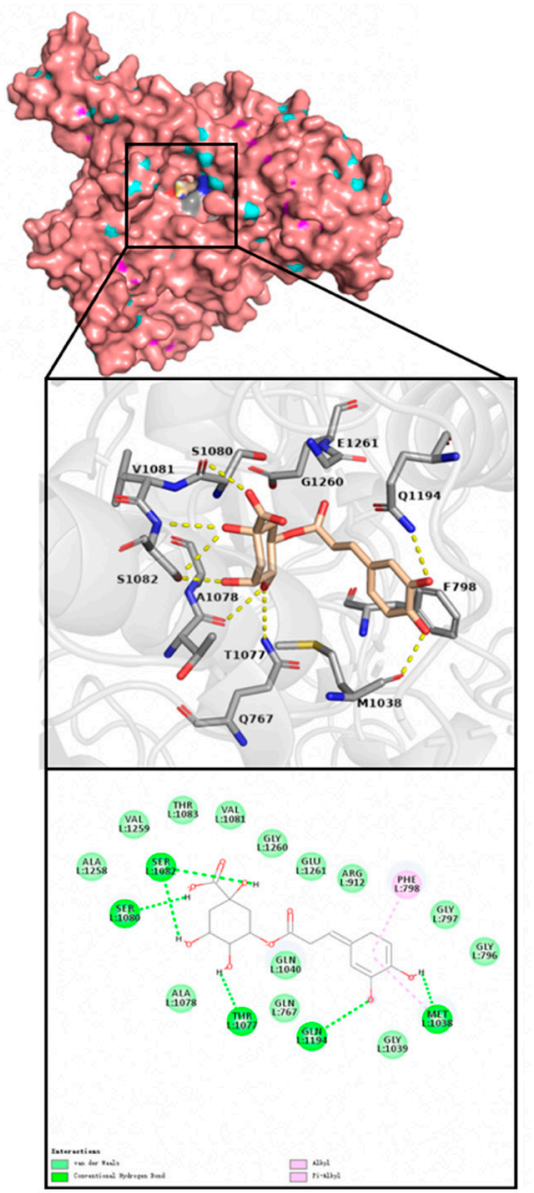

Figure 6. The docked complexes (a) scopoletin with XO and (b) chlorogenic acid with XO. Residues around inhibitor binding.

\section{Discussion}

Despite hyperuricemia being prevalent in young adults and its incidence increasing in the past ten years [19], the development of specific medicine with minor side effects is still rare. Sunflower calathide, which could be used as a byproduct of food and agriculture, showed its potential to lower the effects of high uric acid and perhaps less toxicity than clinical medicine, such as allopurinol, benzbromarone, and febuxostat [20]. To determine 
the active ingredients, we identified two water-soluble active components of SCHE, SP and $\mathrm{CA}$, although their extraction methods remain to be developed.

Scopoletin (6-methoxy-7-hydroxycoumarin), a naturally occurring phenolic coumarin isolated from medicinal herbs [21,22], has been verified to lower UA levels in hyperuricemic mice induced by potassium oxyzinate [23] or yeast extract/potassium oxyzinate [24], even if the uricase acts in parallel on hyperuricemic mice; thus, it is essential to investigate the regulation of urate transporters and $\mathrm{XO}$ activities in vitro. The same is true for chlorogenic acid, one of the most abundant polyphenols in herbs, whose isolation and identification methods have been extensively explored and it could be extracted from Eucommia ulmoides (Oliver) leaf [25], green coffee [26], and Eupatorium adenophorum (Spreng) [27], etc. While chlorogenic acid also contributes to hyperuricemia, gout, and inflammation [28-30], the evidence on the potential molecular mechanism of the regulation of urate transporters is lacking. Given the bioactive ingredients in sunflower calathide, the mechanism of scopoletin and chlorogenic acid was investigated theoretically and experimentally in this paper.

Consistent with a previous study, in this article we showed that SP and CA have excellent potential as antioxidants [31]. We also demonstrated that the SCHE has the ability to reduce UA-induced oxidase stress stimulated by UA. Additionally, the urate resorptive transporter URAT1 (solute carrier family 22 member 12) [32] and the glucose transporter GLUT9 (solute carrier family 2 member 9) play crucial roles in urate transport associated with hyperuricemia [33,34]. Therefore, in this study, we used HEK293T cells to determine the regulation of urate transporters with our compounds of interests. Although the UA treatment alone in HEK293T cells did not affect the expression of urate transporters, we found that the SCHE downregulated the expression of URAT1 and GLUT9 in parallel with CA. On the contrary, the significant activation of the GLUT9 transporter occurs in SP treatment, which implies that SP cannot be applied to promote UA excretion, despite its inhibition of the formation of UA and the inhibitory activity of $\mathrm{XO}\left(\mathrm{IC}_{50}=577.7 \mu \mathrm{M}\right)$. Based on the docking results, both SP and CA displayed the same binding pockets as xanthine and closed to the $\mathrm{Mo}=\mathrm{S}$ center, which just was the important functional site of $\mathrm{XO}$ [35]. Moreover, the affinity of XO-CA was much stronger than that of the SP below $260 \mu \mathrm{M}$, which was consistent with the in vitro results according to the $\mathrm{XO}$ inhibition curve. Accordingly, CA and SP probably interfered with the interaction of xanthine and $\mathrm{XO}$, thus competitively inhibit the production of UA.

Overall, the results showed that CA, rather than SP, not only achieved the downregulation of the expression of URAT1 and GLUT9, but also inhibited the formation of UA in vitro and the stable binding to the traditional active pocket of XO. It can be concluded that chlorogenic acid has an excellent affinity to $\mathrm{XO}$, which could be used as a potential therapy for the treatment of hyperuricemia.

Given the above, future studies are needed to determine other potential ingredients in sunflower calathide. Moreover, it might be of great significance to develop drugs with chlorogenic acid and scopoletin that are widespread in botany as alternative antihyperuricemia therapy.

\section{Conclusions}

To summarize, the present study revealed the potential mechanism associated with anti-hyperuricemia effects of the extract of Helianthus annuus L. calathide. Chlorogenic acid was not only an efficient inhibitor of URAT1 and GLUT9 involved in UA excretion, but also a competitive inhibitor of XO. The current study lays material basis for developing Helianthus annuus $\mathrm{L}$. as herbal medicine and alternative therapy.

Author Contributions: H.D.: conceptualization, data curation, formal analysis, methodology, project administration, and writing-original draft. S.L.: preparation of the electrophoresis gel. W.L. and X.F.: funding acquisition, supervision, and review. All authors have read and agreed to the published version of the manuscript. 
Funding: This study was financially supported by a grant from the National Natural Science Foundation of China (No.31670795).

Conflicts of Interest: The authors confirm that no conflict of interest affect the present study.

\section{References}

1. Benn, C.L.; Dua, P.; Gurrell, R.; Loudon, P.; Pike, A.; Storer, R.I.; Vangjeli, C. Physiology of Hyperuricemia and Urate-Lowering Treatments. Front. Med. (Lausanne) 2018, 5, 160. [CrossRef]

2. Choi, H.K.; Ford, E.S. Prevalence of the metabolic syndrome in individuals with hyperuricemia. Am. J. Med. 2007, 120, 442-447. [CrossRef]

3. Mendez Landa, C.E. Renal Effects of Hyperuricemia. Contrib. Nephrol. 2018, 192, 8-16. [CrossRef] [PubMed]

4. Becker, M.A.; Schumacher, H.R.; Wortmann, R.L.; MacDonald, P.A.; Eustace, D.; Palo, W.A.; Streit, J.; Joseph-Ridge, N. Febuxostat Compared with Allopurinol in Patients with Hyperuricemia and Gout. N. Engl. J. Med. 2005, 353, 2450-2461. [CrossRef]

5. Iglesias, M.T.; Lozano, J.E. Extraction and characterization of sunflower pectin. J. Food Eng. 2004, 62, 215-223. [CrossRef]

6. Sobol, I.V. The Use of Highly Purified Sunflower Pectin in Functional Foods. Food Process. Technol. 2016, $43,90-95$.

7. Peng, X.; Yang, G.; Shi, Y.; Zhou, Y.; Zhang, M.; Li, S. Box-Behnken design based statistical modeling for the extraction and physicochemical properties of pectin from sunflower heads and the comparison with commercial low-methoxyl pectin. Sci. Rep. 2020, 10, 3595. [CrossRef]

8. Li, L.; Teng, M.; Liu, Y.; Qu, Y.; Zhang, Y.; Lin, F.; Wang, D. Anti-Gouty Arthritis and Antihyperuricemia Effects of Sunflower (Helianthus annuus) Head Extract in Gouty and Hyperuricemia Animal Models. Biomed Res. Int. 2017, 2017, 5852076. [CrossRef] [PubMed]

9. Liu, G.; Chen, X.F.; Lu, X.; Zhao, J.Y.; Li, X.L. Sunflower head enzymatic hydrolysate relives hyperuricemia by inhibiting crucial proteins (xanthine oxidase, adenosine deaminase, uric acid transporter1) and restoring gut microbiota in mice. J. Funct. Foods 2020, 72. [CrossRef]

10. Lee, P.C. Developmental changes of adenosine deaminase, xanthine oxidase, and uricase in mouse tissues. Dev. Biol. 1973, 31, 227-233. [CrossRef]

11. Lu, J.; He, Y.; Cui, L.; Xing, X.; Liu, Z.; Li, X.; Zhang, H.; Li, H.; Sun, W.; Ji, A.; et al. Hyperuricemia predisposes to the onset of diabetes via promoting pancreatic $\beta$-cell death in uricase-deficient Male mice. Diabetes 2020, 69, 1149-1163. [CrossRef]

12. Zhou, H.; Zhong, G.; Bai, J.; Li, X.; Peng, W.; Zhang, L.; Li, J. Development of a fluorescence-based assay for screening of urate transporter 1 inhibitors using 6-carboxyfluorescein. Anal. Biochem. 2021, 626, 114246. [CrossRef]

13. Chen, Y.; Zhao, Z.; Li, Y.; Li, L.; Jiang, Y.; Cao, Y.; Zhou, P.; Wu, T.; Pang, J. Characterizations of the Urate Transporter, GLUT9, and Its Potent Inhibitors by Patch-Clamp Technique. SLAS Discov. 2021, 26, 450-459. [CrossRef] [PubMed]

14. Xu, N.; Lu, Y.; Hou, J.; Liu, C.; Sun, Y. A Polysaccharide Purified from Morchella conica Pers. Prevents Oxidative Stress Induced by H2O2 in Human Embryonic Kidney (HEK) 293T Cells. Int. J. Mol. Sci. 2018, 19, 4027. [CrossRef] [PubMed]

15. Yu, Z.P.; Kan, R.T.; Wu, S.J.; Guo, H.; Zhao, W.Z.; Ding, L.; Zheng, F.P.; Liu, J.B. Xanthine oxidase inhibitory peptides derived from tuna protein: Virtual screening, inhibitory activity, and molecular mechanisms. J. Sci. Food Agric. 2021, 101, 1349-1354. [CrossRef] [PubMed]

16. Li, R.a.; Song, W.a.; Qiao, X.a.; Liu, J.b.; Liang, H.a.; Ye, M.a. Chemical profiling of Scutellaria barbata by ultra high performance liquid chromatography coupled with hybrid quadrupoleorbitrap mass spectrometry(Article). J. Chin. Pharm. Sci. 2015, 24, 635-646. [CrossRef]

17. Sriramulu, D.K.; Lee, S.G. Effect of molecular properties of the protein-ligand complex on the prediction accuracy of AutoDock. J. Mol. Graph. Model. 2021, 106, 107921. [CrossRef]

18. Cao, H.; Pauff, J.; Hille, R. Substrate orientation and the origin of catalytic power in xanthine oxidoreductase. Indian J. Chem. Sect. A Inorg. Phys. Theor. Anal. 2011, 50, 355-362.

19. Qi, D.; Liu, J.; Wang, C.; Wang, L.; Zhang, X.; Lin, Q.; Tu, J.; Wang, J.; Ning, X.; Cui, J. Sex-specific differences in the prevalence of and risk factors for hyperuricemia among a low-income population in China: A cross-sectional study. Postgrad. Med. 2020, 132, 559-567. [CrossRef]

20. Chou, H.W.; Chiu, H.T.; Tsai, C.W.; Ting, I.W.; Yeh, H.C.; Huang, H.C.; Kuo, C.C.; Group, C.K.R. Comparative effectiveness of allopurinol, febuxostat and benzbromarone on renal function in chronic kidney disease patients with hyperuricemia: A 13-year inception cohort study. Nephrol. Dial. Transplant. 2018, 33, 1620-1627. [CrossRef] [PubMed]

21. Li, J.; Wu, J. Scopolin, a glycoside form of the phytoalexin scopoletin, is likely involved in the resistance of Nicotiana attenuata against Alternaria alternata. J. Plant Pathol. 2016, 98, 641-644. [CrossRef]

22. Firmansyah, A.; Winingsih, W.; Manobi, J.D.Y. Review of Scopoletin: Isolation, Analysis Process, and Pharmacological Activity. Biointerface Res. Appl. Chem. 2021, 11, 12006-12019. [CrossRef]

23. Ding, Z.; Dai, Y.; Wang, Z. Hypouricemic action of scopoletin arising from xanthine oxidase inhibition and uricosuric activity. Planta Med. 2005, 71, 183-185. [CrossRef] [PubMed]

24. Zeng, Y.; Ma, Y.; Yang, Z.; Mao, J.; Zheng, Y. Antihyperuricemic efficacy of Scopoletin-loaded Soluplus micelles in yeast extract/potassium oxonate-induced hyperuricemic mice. Drug Dev. Ind. Pharm. 2020, 46, 1550-1557. [CrossRef] [PubMed]

25. Li, H.; Zhao, J.; Deng, W.; Li, K.; Liu, H. Effects of chlorogenic acid-enriched extract from Eucommia ulmoides Oliver leaf on growth performance and quality and oxidative status of meat in finishing pigs fed diets containing fresh or oxidized corn oil. J. Anim. Physiol. Anim. Nutr. 2020, 104, 1116-1125. [CrossRef]

26. Farah, A.; Monteiro, M.; Donangelo, C.M.; Lafay, S. Chlorogenic acids from green coffee extract are highly bioavailable in humans. J. Nutr. 2008, 138, 2309-2315. [CrossRef] 
27. Liu, B.; Dong, B.; Yuan, X.; Kuang, Q.; Zhao, Q.; Yang, M.; Liu, J.; Zhao, B. Enrichment and separation of chlorogenic acid from the extract of Eupatorium adenophorum Spreng by macroporous resin. J. Chromatogr. B Anal. Technol. Biomed. Life Sci. 2016, 1008, 58-64. [CrossRef]

28. Ferraz-Filha, Z.S.; Ferrari, F.C.; Araújo, M.C.d.P.M.; Bernardes, A.C.F.P.F.; Saúde-Guimarães, D.A. Effects of the Aqueous Extract from Tabebuia roseoalba and Phenolic Acids on Hyperuricemia and Inflammation. Evid.-Based Complement. Alternat. Med. 2017, 2017, 2712108-2712110. [CrossRef]

29. Zhou, X.; Zhang, B.; Zhao, X.; Lin, Y.; Wang, J.; Wang, X.; Hu, N.; Wang, S. Chlorogenic acid supplementation ameliorates hyperuricemia, relieves renal inflammation, and modulates intestinal homeostasis. Food Funct. 2021. [CrossRef]

30. Meng, Z.-Q.; Tang, Z.-H.; Yan, Y.-X.; Guo, C.-R.; Cao, L.; Ding, G.; Huang, W.-Z.; Wang, Z.-Z.; Wang, K.D.G.; Xiao, W.; et al. Study on the anti-gout activity of chlorogenic acid: Improvement on hyperuricemia and gouty inflammation. Am. J. Chin. Med. 2014, 42, 1471-1483. [CrossRef]

31. Dhiman, P.; Malik, N.; Khatkar, A.; Kulharia, M. Antioxidant, xanthine oxidase and monoamine oxidase inhibitory potential of coumarins: A review. Curr. Org. Chem. 2017, 21, 294-304. [CrossRef]

32. Song, D.; Zhao, X.; Wang, F.; Wang, G. A brief review of urate transporter 1 (URAT1) inhibitors for the treatment of hyperuricemia and gout: Current therapeutic options and potential applications. Eur. J. Pharmacol. 2021, 907, 174291. [CrossRef] [PubMed]

33. Shin, H.J.; Takeda, M.; Enomoto, A.; Fujimura, M.; Miyazaki, H.; Anzai, N.; Endou, H. Interactions of urate transporter URAT1 in human kidney with uricosuric drugs. Nephrology 2011, 16, 156-162. [CrossRef] [PubMed]

34. Claverie-Martin, F.; Trujillo-Suarez, J.; Gonzalez-Acosta, H.; Aparicio, C.; Justa Roldan, M.L.; Stiburkova, B.; Ichida, K.; MartínGomez, M.A.; Herrero Goñi, M.; Carrasco Hidalgo-Barquero, M.; et al. URAT1 and GLUT9 mutations in Spanish patients with renal hypouricemia. Clin. Chim. Acta 2018, 481, 83-89. [CrossRef]

35. Cao, H.; Hall, J.; Hille, R. Substrate Orientation and Specificity in Xanthine Oxidase: Crystal Structures of the Enzyme in Complex with Indole-3-acetaldehyde and Guanine. Biochemistry 2014, 53, 533-541. [CrossRef] 